\title{
A COMPARISON OF TECHNIQUE SURVIVAL IN CANADIAN PERITONEAL DIALYSIS AND HOME HEMODIALYSIS PATIENTS
}

\author{
Emilie Trinh \\ Department of Epidemiology, Biostatistics and Occupational Health \\ McGill University, Montreal
}

Supervisor:

Dr. James Hanley, PhD

Co-Supervisor:

Dr. Christopher Chan, MD

\begin{abstract}
A thesis submitted to McGill University in partial fulfillment of the requirements of the degree of Master of Science in Epidemiology
\end{abstract}

March 2019

(C)2019 Emilie Trinh 


\section{Acknowledgments}

I am extremely grateful to my thesis supervisors, Dr. Christopher Chan and Dr. James Hanley, for their contribution, constructive feedback, help and advice for my master's thesis.

I am also thankful to Dr. Jeffrey Perl for his valuable input and guidance and Dr. Annie-Claire Nadeau-Fredette for her assistance with data analysis and interpretation.

Finally, I wish to thank my husband Julien for his unwavering support and my family and friends for their continued encouragement during my master's in epidemiology. 


\section{Contribution of Authors}

This submission is a manuscript-based thesis. Chapter 2 (A Comparison of Technique Survival in Canadian Peritoneal Dialysis and Home Hemodialysis Patients) has been submitted to the journal Nephrology Dialysis Transplantation and is pending peer review.

Emilie Trinh was responsible for primary authorship of Chapter 1 and Chapter 2. She was responsible for study design, data analysis under the supervision of Dr. James Hanley, interpretation of results and preparation of Chapter 2 in collaboration with all co-authors.

Dr. James Hanley contributed to design, analysis, interpretation of data and revision of Chapters 1 and 2.

Dr. Annie-Claire Nadeau-Fredette contributed to data interpretation and revision of the manuscript (Chapter 2).

Dr. Jeffrey Perl contributed to design, and revision of the manuscript (Chapter 2).

Dr. Christopher Chan contributed to design, analysis, interpretation of data and revision of the Chapters 1 and 2. 


\section{List of Abbreviations}

$\begin{array}{ll}\text { AHR } & \text { adjusted hazard ratio } \\ \text { APD } & \text { automated peritoneal dialysis } \\ \text { AVF } & \text { arteriovenous fistula } \\ \text { AVG } & \text { arteriovenous graft } \\ \text { BMI } & \text { body mass index } \\ \text { CAPD } & \text { continuous ambulatory peritoneal dialysis } \\ \text { CORR } & \text { Canadian Organ Replacement Register } \\ \text { CVC } & \text { central venous catheter } \\ \text { ESKD } & \text { end-stage kidney disease } \\ \text { HD } & \text { hemodialysis } \\ \text { HHD } & \text { home hemodialysis } \\ \text { HR } & \text { propensity score } \\ \text { PD } & \text { hazard ratio } \\ \text { RRT } & \text { peritoneal dialysis } \\ & \end{array}$




\section{Table of Content}

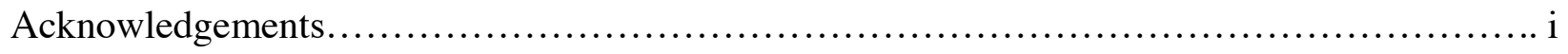

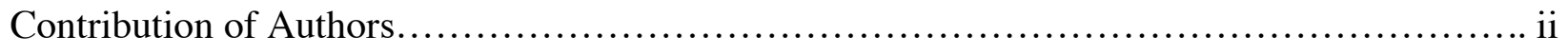

List of Abbreviations..............................................................

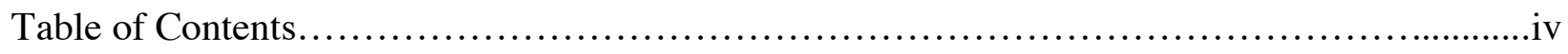

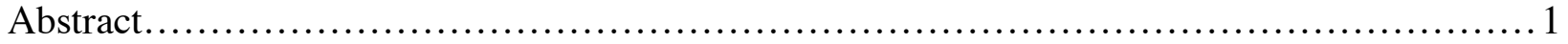

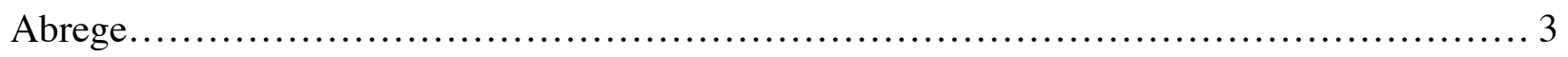

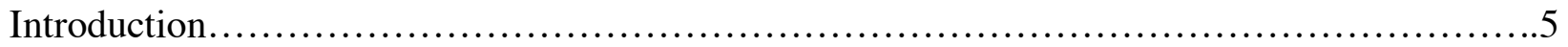

Chapter 1: Technique Survival in Home Dialysis : A Narrative Review......................6 6

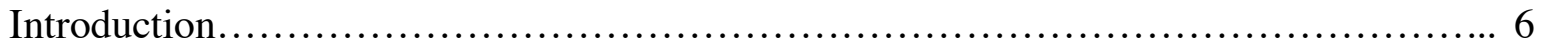

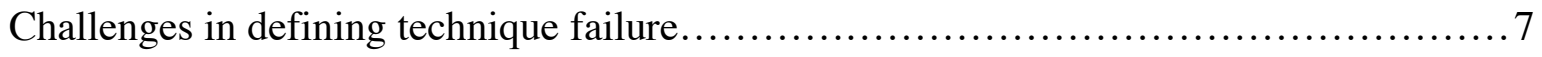

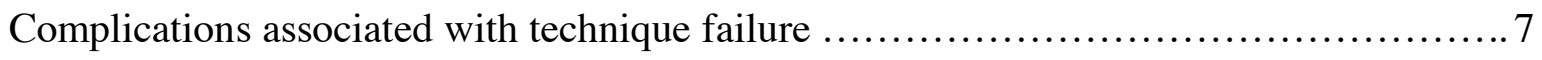

Technique Survival in Peritoneal Dialysis....................................... 8

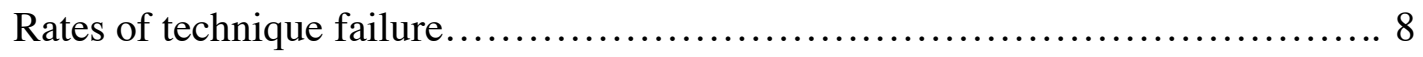

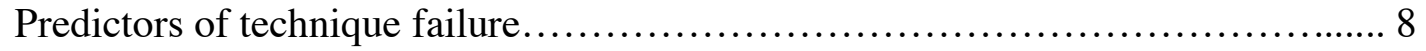

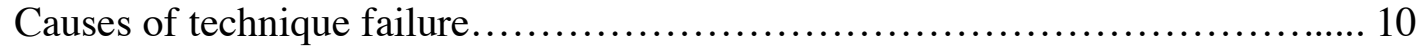

Technique Survival in Home Hemodialysis....................................... 10

Rates of technique failure............................................ 10

Predictors of technique failure.......................................... 10

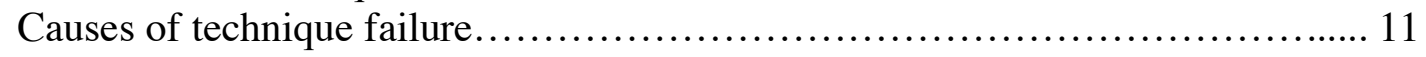

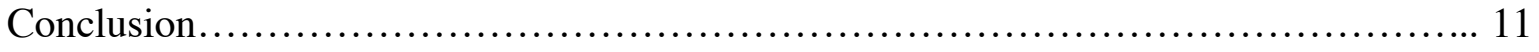

References.................................................................... 12

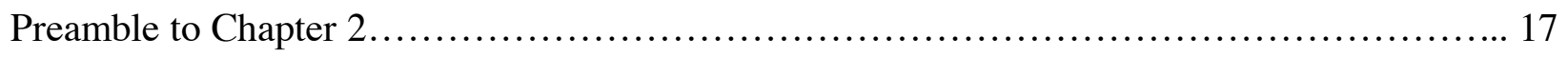

Chapter 2: A Comparison of Technique Survival in Canadian Peritoneal Dialysis and Home Hemodialysis Patients..............................................................

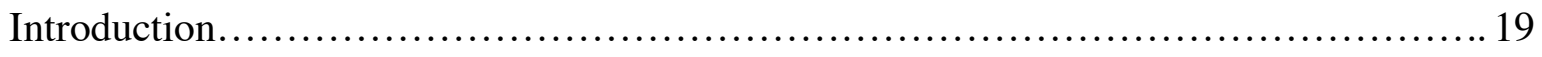


Methods.

Results

Discussion 26

Conclusion

Acknowledgments. 31

Disclosures 31

References. 32

Tables 36

Table 1: Patient characteristics at home dialysis initiation, 2000 to 2012 ....

Table 2: Adjusted hazard ratios for technique failure comparing home hemodialysis with peritoneal dialysis.

Table 3: Association of patient characteristics with technique failure 39

Table 4: Causes of technique failure in peritoneal dialysis and home hemodialysis patients.

Table 5: Technique failure event rates by different cut-off definitions.....

Figures.

Figure 1: Crude rates of technique failure by time from dialysis initiation in home hemodialysis and peritoneal dialysis.

Figure 2: Unadjusted technique survival comparison between home hemodialysis and peritoneal dialysis in Canada 2000-2012.

Figure 3: Adjusted hazard ratios of technique failure comparing home hemodialysis with peritoneal dialysis in specific patient subgroups

Figure 4: Crude rates of technique failure over time in home hemodialysis and peritoneal dialysis. .46 
Chapter 3: Conclusion............................................................... 50 


\begin{abstract}
Background: High discontinuation rates remain a challenge for home hemodialysis (HHD) and peritoneal dialysis (PD). We compared technique failure risks among Canadian patients receiving HHD and PD.
\end{abstract}

Methods: Using the Canadian Organ Replacement Register, we studied adult patients who initiated HHD or PD within 1 year of beginning dialysis between 2000-2012, with follow-up until December 31 2013. Technique failure was defined as a transfer to any alternative modality for a period of $\geq 60$ days. We compared technique survival between HHD and PD using a Fine and Gray competing risk model. Secondary outcomes included the time dependence of technique survival, the association of patient characteristics with technique failure, causes of technique failure and changes in technique failure rates over time

Results: Between 2000-2012, 15,314 patients were treated with a home dialysis modality within 1 year of dialysis initiation: 14,461 on PD and 853 on HHD. Crude technique failure rates were highest during the first year of therapy for both home modalities. During the entire period of follow-up, technique failure was lower with HHD compared to PD (adjusted hazard ratio [AHR] 0.79; 95\% CI 0.69-0.90). However, the relative technique failure risk was not proportional over time and the beneficial effect of HHD was only apparent after the first year of dialysis. Comparisons also varied among subgroups and the superior technique survival associated with HHD relative to PD was less pronounced in more recent years and among older patients. Predictors of technique failure also differed between modalities. While obesity, smoking and small facility size were associated with higher technique failure in both PD and HHD, the effect of age and gender differed. Furthermore, the majority of home dialysis discontinuation occurred for medical 
reasons in $\mathrm{PD}(38 \%)$ while the majority of HHD patients experienced technique failure due to social reasons or inadequate resources $(50 \%)$.

Conclusions: In this Canadian study of home dialysis patients, HHD was associated with better technique survival compared to PD. However, patterns of technique failure differed significantly among these modalities. Strategies to improve patient retention across all home dialysis modalities are needed. 


\section{Abrégé}

Introduction: Les taux d'abandon élevés restent un défi pour l'hémodialyse à domicile et la dialyse péritonéale. Le but de notre étude était de comparer les risques d'échec technique entre l'hémodialyse à domicile et la dialyse péritonéale au Canada.

Méthodes: À l'aide du Registre CORR (Canadian Organ Replacement Register), nous avons étudié les patients adultes ayant initié l'hémodialyse à domicile ou la dialyse péritonéale au cours de l'année suivant le début de la dialyse entre 2000 et 2012. Nous avons défini l'échec technique comme un transfert vers une modalité de dialyse alternative pour une période de $\geq 60$ jours. Nous avons comparé la survie technique entre l'hémodialyse à domicile et la dialyse péritonéale en utilisant un modèle de risque concurrent Fine and Gray. Nous avons aussi examiné la dépendance temporelle de la survie technique, l'association des caractéristiques du patient avec l'échec technique, les différentes causes d'échec technique et la variation des taux d'échec technique au fil du temps.

Résultats: Entre 2000 et 2012, 15314 patients ont été traités avec une modalité de dialyse à domicile dans l'année suivant le début de la dialyse: 14461 sous dialyse péritonéale et 853 sous hémodialyse à domicile. Les taux d'échec technique étaient les plus élevés au cours de la première année de traitement pour les deux modalités à domicile. Pendant toute la période de suivi, l'échec technique était plus faible avec l'hémodialyse à domicile que dialyse péritonéale (risque ajusté [AHR] 0,79; 95\% CI 0,69-0,90). Cependant, le risque relatif d'échec technique n'était pas proportionnel au fil du temps et l'effet bénéfique de l'hémodialyse à domicile n'était apparent qu'après la première année de dialyse. Les comparaisons variaient également entre les sousgroupes et la survie technique supérieure associée à l'hémodialyse à domicile par rapport à la dialyse péritonéale était moins prononcée au cours des dernières années et chez les patients plus 
âgés. Les facteurs prédictifs d'échec technique différaient également d'une modalité à l'autre. Alors que l'obésité, le tabagisme et les centres traitants plus petits étaient associés à un échec technique plus élevé, à la fois pour l'hémodialyse à domicile et la dialyse péritonéale, les effets de l'âge et du sexe était différents. En outre, la majorité des discontinuations de dialyse à domicile ont eu lieu pour des raisons médicales pour la dialyse péritonéale (38\%), tandis que la majorité des patients sous hémodialyse à domicile ont connu un échec technique pour des raisons sociales ou des ressources insuffisantes $(50 \%)$.

Conclusions: Au Canada, l'hémodialyse à domicile était associée à une meilleure survie technique par rapport à la dialyse péritonéale. Cependant, les variations d'échec technique différaient de manière significative entre ces modalités. Des stratégies visant à améliorer la survie technique chez les patients sous toutes modalités de dialyse à domicile sont nécessaires. 


\section{Introduction}

End-stage kidney disease is associated with increased mortality, morbidity and impaired quality of life. Peritoneal dialysis (PD) and home hemodialysis (HHD) are renal replacement modalities that allow patients to manage their own treatment in the comfort of their own home and offer several clinical benefits. With worldwide growing interest in increasing utilization of home dialysis, less is known on how to prevent discontinuation of these modalities. Indeed, high rates of discontinuation ("technique failure") remain a challenge. While previous studies have examined some of the predictors of technique failure for PD and HHD, few studies have compared technique survival between these home modalities.

Our first objective was to review the literature on what is currently known about all aspects of technique survival for both PD and HHD, including what definitions are used, what are the reported rates of technique failure, what are the clinical and sociodemographic predictors of technique failure and what are the most common causes of discontinuation.

Our second objective was to compare the patterns and trajectory of technique survival between these home modalities in a multicenter Canadian cohort to have a better understanding on technique survival. 


\section{Chapter 1:}

\section{Technique Survival in Home Dialysis: A Narrative Review}

Home dialysis therapies, including home hemodialysis (HHD) and peritoneal dialysis (PD), offer several benefits for patients with end-stage kidney disease when compared with patients on conventional in-center thrice-weekly hemodialysis (HD). HHD is associated with improvements in blood pressure control, abnormalities of mineral metabolism, sleep quality, and regression of left ventricular hypertrophy ${ }^{1-6}$. In contrast, peritoneal dialysis $(\mathrm{PD})$ is associated with better preservation of residual kidney function, avoidance of vascular access complications, and lower infection rates. ${ }^{7}$ In addition to numerous clinical benefits, many studies have also shown that home dialysis modalities are associated with improved quality of life ${ }^{2,8-10}$ and significantly lower $\operatorname{costs}^{11}$ when compared to in-center HD. Moreover, these modalities allow patients the autonomy of directing their own treatment as well as the flexibility to adjust their dialysis treatment schedule while avoiding the time and cost of frequent travel to a dialysis center. Despite these advantages, in-center conventional HD remains the most common form of renal replacement therapy in at least $80 \%$ of ESRD patients in the majority of the world. ${ }^{12}$ However, interest in home dialysis has grown significantly in recent years. In Canada, home dialysis is achieved in $25-30 \%$ of patients ${ }^{12}$ with ongoing efforts to increase the incidence of home dialysis therapies. However, high rates of discontinuation, defined as "technique failure", remain a challenge. In fact, rates have been reported in up to $25 \%$ of patients within the first year of therapy for both HHD and PD. ${ }^{13-17}$ Little is known on what patient or center-specific characteristics predict technique failure and what factors are potentially modifiable. 


\section{Challenges in defining technique failure}

Technique failure is defined as a transfer to an alternative dialysis modality for a predetermined amount of time. It remains unknown what optimal time period most accurately defines technique failure or is associated with adverse outcomes. Studies have used a variety of definition including $30,45,60,90$, and 180-days. As changes may often be temporary in the context of an acute illness or a hospitalization, too short a time frame used for the definition of technique failure may not accurately represent true discontinuation as patients may return to their initial modality. Conversely, using a longer time frame may give rise to patients getting loss to follow-up or developing other complications unrelated to technique failure. Moreover, another challenge is that some modality changes may be due to inadequate resources (i.e. a patient relocates to a jurisdiction where home dialysis is not supported) and may not truly represent technique failure.

Given the lack of a standardized definition of technique failure, it is difficult to accurately determine clinical implications on outcomes and compare studies. In a recent study of PD patients by Lan et al. using the Australia and New Zealand Dialysis and Transplant Registry, the likelihood to return to PD was highest when using a 30-day definition but was very small with definitions $>180$ days. $^{18}$ A 30-day definition allowed to capture acute intercurrent illness contributing to increased morbidity and mortality while a 180-day definition provided a time-frame where it was unlikely the patient would return to PD. As such, the authors emphasized that different definitions addressed distinct clinical aspects.

\section{Complications associated with Technique Failure}

Technique failure usually leads to transition to conventional in-center HD. ${ }^{19,20}$ For PD patients, this transition is often in context of an acute medical complication, most commonly PD peritonitis, 
failure of PD to provide adequate dialysis or PD catheter malfunction. ${ }^{20}$ Therefore, this switch is may be unplanned. ${ }^{19}$ With an unplanned transition, patients likely initiate HD with a central venous catheter and it is well recognized that there is a higher mortality associated with unplanned HD initiation, especially with catheter use and its associated higher infectious risks. ${ }^{21,22}$ Moreover, this transition period may also be associated with psychosocial distress and changes in quality of life. For HHD, modality change is also associated with poor outcomes. In a study by Shah et al., the 90-day mortality in patients who experienced HHD technique failure was significantly higher (26\%) compared to patients who remained on HHD. ${ }^{23}$ Nevertheless, the transition period from one renal replacement therapy to another is a particularly vulnerable time, both in context of the acute medical issues leading to technique failure, but also due to the unplanned nature of the transition. Therefore, it is imperative to find strategies not only to prevent technique failure, but also to ensure a better and smoother transition between renal replacement modality.

\section{Technique Survival in Peritoneal Dialysis}

\section{Rates of technique failure}

Rates of technique failure vary considerably in the literature. ${ }^{15-17,20,24-26}$ Discontinuation appear to be highest during the first year of therapy, with rates varying from $4.9 \%$ to $26.2 \% .{ }^{16,17,24,25}$ Median time to technique failure has been reported at about 2 years. ${ }^{17,27}$

\section{Predictors of technique failure}

Various patient and center-specific factors appear to be associated with technique failure. A higher degree of comorbidity appears to lead to increased risk, with BMI, diabetes, smoking, 
cardiovascular disease, peripheral vascular disease and chronic lung disease having all been shown to predict technique failure. ${ }^{15,24,26}$ In contrast, the effect of age on technique failure is variably reported. In some studies, older patients have been shown to have increased technique failure risk $^{16,24,26}$ whereas other studies have shown a lower risk in patients $>65$ years old. ${ }^{28}$ This may be related to increasing utilization of assisted PD in older patients in some areas of the world which may be associated with better technique survival. ${ }^{29}$

Sociodemographic factors have also been shown to be strong predictors of technique survival. In fact, studies have demonstrated racial disparities both in the use of and in outcomes with home dialysis. ${ }^{30}$ In a recent study by Mehrotra et al in the US, Black patients treated with PD had a much higher risk of technique failure compared to Caucasians. ${ }^{30}$ Furthermore, employment status has also been identified as a determinant of technique survival with full-time employment having been demonstrated to be a strong and independent predictor of better technique survival. ${ }^{31,32}$ In a Chinese study, lower income was also found to predict treatment failure. ${ }^{33}$

Other factors that have been demonstrated to impact technique survival have included timing of referral to a nephrologist and center-specific factors. Late referral to a nephrologist has consistently been shown to be associated with higher technique failure risk. ${ }^{16,17,26}$ Furthermore, center experience with PD appears to be an important determinant of technique success. Indeed, many studies including a systematic review have demonstrated that larger centers and centers with a higher proportions of PD patients have lower rates of technique failure. ${ }^{26,34-36}$ These findings likely reflect the degree of experience managing $\mathrm{PD}$ patients and their associated complications in addition to availability of resources. 


\section{Causes of technique failure}

Although exact causes for PD discontinuation are not always discernable in retrospective studies, the most common reported reasons for technique failure have been mechanical causes (leaks, catheter dysfunction, hernias, etc.), infection, inadequate dialysis and psychosocial issues. ${ }^{20,24}$

\section{Technique Survival in Home Hemodialysis}

\section{Rates of technique failure}

The complex and frequent nature of HHD may lead to patient and/or caregiver burnout, thus leading to discontinuation with transfer to in-center conventional HD. Reported rates of technique failure vary considerably in the literature with 1 -year rates between 2 and $25 \% .^{13,37}$ In a Canadian multicenter study from 1994-2006, technique survival was $98 \%$ and $95 \%$ at 1 and 5 years, respectively. ${ }^{38}$ Conversely, in an Australian cohort, technique survival rates were reported at $90 \%$ and $68 \%$ at 1 and 5 years. ${ }^{39}$ More recently, a US study described much higher discontinuation rates of $25 \%$ at 1 year and $35 \%$ at 2 years. ${ }^{40}$ These significant differences in rates of technique failure are likely related to center-specific practice patterns, evolving patient characteristics and likely less strict selection criteria in recent years with patients with a higher degree of comorbidity being treated with HHD.

\section{Predictors of technique failure}

Compared to PD, less is known about factors associated with technique failure in HHD. Clinical characteristics predicting technique failure have included age, diabetes, and heart failure. ${ }^{37,38,40}$ 
Socioeconomic factors also appear to contribute importantly to technique failure risk. In fact, substance use and urban residence have both been shown to predict HHD discontinuation. ${ }^{37,40}$ More recently, a US cohort study by Mehrotra et al. demonstrated that Black patients were more likely to experience technique failure, even after adjustment for clinical factors, thus further supporting an important role for socioeconomic status. ${ }^{30}$ Center characteristics have also been shown to be important predictors of technique failure. In a multicenter Canadian cohort study of 7 treating centers, Pauly et al demonstrated that there were significant variations in rates of technique failure among the treating centers that were not attributable to differences in patient characteristics. $^{41}$

\section{Causes of technique failure}

As compared to PD, less is known about exact causes of discontinuation of HHD. In a recent study of 94 Canadian HHD patients, the reported causes for modality change were medical instability (65\%), patient burnout (13\%), caregiver burnout (13\%) and patient choice $(9 \%){ }^{23}$

\section{Conclusion}

With increasing efforts to encourage home modalities, it is imperative to better understand technique survival and find strategies to help maintain patients on the home therapy of their choosing. Can hsigh-risk patients be identified early and managed appropriately? Can there be improvements with patient training? What center-specific practices are potentially modifiable to improve technique survival? Moreover, it is also important to note that by expanding patient selection criteria to increase utilization of home dialysis, this may also lead to higher discontinuation rates. 


\section{References}

1. Chan CT, Floras JS, Miller JA, Richardson RM, Pierratos A. Regression of left ventricular hypertrophy after conversion to nocturnal hemodialysis. Kidney Int. 2002;61(6):2235-2239.

2. Culleton BF, Walsh M, Klarenbach SW, et al. Effect of frequent nocturnal hemodialysis vs conventional hemodialysis on left ventricular mass and quality of life: a randomized controlled trial. JAMA. 2007;298(11):1291-1299.

3. Hanly PJ, Pierratos A. Improvement of sleep apnea in patients with chronic renal failure who undergo nocturnal hemodialysis. N Engl J Med. 2001;344(2):102-107.

4. Susantitaphong P, Koulouridis I, Balk EM, Madias NE, Jaber BL. Effect of frequent or extended hemodialysis on cardiovascular parameters: a meta-analysis. Am J Kidney Dis. 2012;59(5):689-699.

5. Tennankore K, Nadeau-Fredette AC, Chan CT. Intensified home hemodialysis: clinical benefits, risks and target populations. Nephrol Dial Transplant. 2014;29(7):1342-1349.

6. Walsh M, Manns BJ, Klarenbach S, Tonelli M, Hemmelgarn B, Culleton B. The effects of nocturnal compared with conventional hemodialysis on mineral metabolism: A randomized-controlled trial. Hemodial Int. 2010;14(2):174-181.

7. Chaudhary K, Sangha H, Khanna R. Peritoneal dialysis first: rationale. Clin J Am Soc Nephrol. 2011;6(2):447-456.

8. Barendse SM, Speight J, Bradley C. The Renal Treatment Satisfaction Questionnaire (RTSQ): a measure of satisfaction with treatment for chronic kidney failure. Am J Kidney Dis. 2005;45(3):572-579. 
9. Juergensen E, Wuerth D, Finkelstein SH, Juergensen PH, Bekui A, Finkelstein FO. Hemodialysis and peritoneal dialysis: patients' assessment of their satisfaction with therapy and the impact of the therapy on their lives. Clin J Am Soc Nephrol. 2006;1(6):1191-1196.

10. Rubin HR, Fink NE, Plantinga LC, Sadler JH, Kliger AS, Powe NR. Patient ratings of dialysis care with peritoneal dialysis vs hemodialysis. JAMA. 2004;291(6):697-703.

11. McFarlane PA, Pierratos A, Redelmeier DA. Cost savings of home nocturnal versus conventional in-center hemodialysis. Kidney Int. 2002;62(6):2216-2222.

12. USRDS. Annual Data Report. 2015; Available from: https://www.usrds.org/adr.aspx. Available at. Accessed July 8, 2016.

13. Seshasai RK, Mitra N, Chaknos CM, et al. Factors Associated With Discontinuation of Home Hemodialysis. Am J Kidney Dis. 2016;67(4):629-637.

14. See EJ, Johnson DW, Hawley CM, et al. Risk Predictors and Causes of Technique Failure Within the First Year of Peritoneal Dialysis: An Australia and New Zealand Dialysis and Transplant Registry (ANZDATA) Study. Am J Kidney Dis. 2017.

15. Guo A, Mujais S. Patient and technique survival on peritoneal dialysis in the United States: evaluation in large incident cohorts. Kidney Int Suppl. 2003(88):S3-12.

16. Jaar BG, Plantinga LC, Crews DC, et al. Timing, causes, predictors and prognosis of switching from peritoneal dialysis to hemodialysis: a prospective study. BMC Nephrol. 2009;10:3.

17. Lee S, Kim H, Kim KH, et al. Technique failure in Korean incident peritoneal dialysis patients: a national population-based study. Kidney Res Clin Pract. 2016;35(4):245-251. 
18. Lan PG, Clayton PA, Johnson DW, et al. Duration of Hemodialysis Following Peritoneal Dialysis Cessation in Australia and New Zealand: Proposal for a Standardized Definition of Technique Failure. Perit Dial Int. 2016;36(6):623-630.

19. Boissinot L, Landru I, Cardineau E, Zagdoun E, Ryckelycnk JP, Lobbedez T. Is transition between peritoneal dialysis and hemodialysis really a gradual process? Perit Dial Int. 2013;33(4):391-397.

20. Mujais S, Story K. Peritoneal dialysis in the US: evaluation of outcomes in contemporary cohorts. Kidney Int Suppl. 2006(103):S21-26.

21. Lorenzo V, Martn M, Rufino M, Hernandez D, Torres A, Ayus JC. Predialysis nephrologic care and a functioning arteriovenous fistula at entry are associated with better survival in incident hemodialysis patients: an observational cohort study. Am $J$ Kidney Dis. 2004;43(6):999-1007.

22. Perl J, Wald R, McFarlane P, et al. Hemodialysis vascular access modifies the association between dialysis modality and survival. J Am Soc Nephrol. 2011;22(6):1113-1121.

23. Shah N, Reintjes F, Courtney M, et al. Quality Assurance Audit of Technique Failure and 90-Day Mortality after Program Discharge in a Canadian Home Hemodialysis Program. Clin J Am Soc Nephrol. 2017.

24. See EJ, Johnson DW, Hawley CM, et al. Risk Predictors and Causes of Technique Failure Within the First Year of Peritoneal Dialysis: An Australia and New Zealand Dialysis and Transplant Registry (ANZDATA) Study. Am J Kidney Dis. 2018;72(2):188197.

25. Kolesnyk I, Dekker FW, Boeschoten EW, Krediet RT. Time-dependent reasons for peritoneal dialysis technique failure and mortality. Perit Dial Int. 2010;30(2):170-177. 
26. Htay H, Cho Y, Pascoe EM, et al. Multicenter Registry Analysis of Center Characteristics Associated with Technique Failure in Patients on Incident Peritoneal Dialysis. Clin J Am Soc Nephrol. 2017;12(7):1090-1099.

27. Perl J, Wald R, Bargman JM, et al. Changes in patient and technique survival over time among incident peritoneal dialysis patients in Canada. Clin J Am Soc Nephrol. 2012;7(7):1145-1154.

28. Lim WH, Dogra GK, McDonald SP, Brown FG, Johnson DW. Compared with younger peritoneal dialysis patients, elderly patients have similar peritonitis-free survival and lower risk of technique failure, but higher risk of peritonitis-related mortality. Perit Dial Int. 2011;31(6):663-671.

29. Lobbedez T, Verger C, Ryckelynck JP, Fabre E, Evans D. Is assisted peritoneal dialysis associated with technique survival when competing events are considered? Clin J Am Soc Nephrol. 2012;7(4):612-618.

30. Mehrotra R, Soohoo M, Rivara MB, et al. Racial and Ethnic Disparities in Use of and Outcomes with Home Dialysis in the United States. J Am Soc Nephrol. 2016;27(7):21232134.

31. Shen J, Mitani AA, Saxena AB, Goldstein BA, Winkelmayer WC. Determinants of peritoneal dialysis technique failure in incident US patients. Perit Dial Int. 2013;33(2):155-166.

32. Tennankore KK, Na Y, Wald R, Chan CT, Perl J. Short daily-, nocturnal- and conventional-home hemodialysis have similar patient and treatment survival. Kidney Int. 2017. 
33. Wang Q, Hu KJ, Ren YP, et al. The Association of Individual and Regional Socioeconomic Status on Initial Peritonitis and Outcomes in Peritoneal Dialysis Patients: A Propensity Score-Matched Cohort Study. Perit Dial Int. 2016;36(4):395-401.

34. Pieper D, Mathes T, Marshall MR. A systematic review of the impact of center volume in dialysis. BMC Res Notes. 2015;8:812.

35. Afolalu B, Troidle L, Osayimwen O, Bhargava J, Kitsen J, Finkelstein FO. Technique failure and center size in a large cohort of peritoneal dialysis patients in a defined geographic area. Perit Dial Int. 2009;29(3):292-296.

36. Plantinga LC, Fink NE, Finkelstein FO, Powe NR, Jaar BG. Association of peritoneal dialysis clinic size with clinical outcomes. Perit Dial Int. 2009;29(3):285-291.

37. Jayanti A, Nikam M, Ebah L, Dutton G, Morris J, Mitra S. Technique survival in home haemodialysis: a composite success rate and its risk predictors in a prospective longitudinal cohort from a tertiary renal network programme. Nephrol Dial Transplant. 2013;28(10):2612-2620.

38. Pauly RP, Maximova K, Coppens J, et al. Patient and technique survival among a canadian multicenter nocturnal home hemodialysis cohort. Clinical Journal of the American Society of Nephrology. 2010;5(10):1815-1820.

39. Jun M, Jardine MJ, Gray N, et al. Outcomes of extended-hours hemodialysis performed predominantly at home. Am J Kidney Dis. 2013;61(2):247-253.

40. Seshasai RK, Mitra N, Chaknos CM, et al. Factors associated with discontinuation of home hemodialysis. American Journal of Kidney Diseases. 2016;67(4):629-637.

41. Pauly RP, Rosychuk RJ, Usman I, et al. Technique Failure in a Multicenter Canadian Home Hemodialysis Cohort. Am J Kidney Dis. 2018. 


\section{Preamble to Chapter 2}

With increasing evidence of clinical benefits with home dialysis, efforts are being made to increase uptake of home dialysis modalities. Many centers are even promoting a "home first" approach. However, in addition to encouraging increasing utilization of home dialysis modalities, it is also imperative to elucidate the best strategies in order to maintain patients on these therapies. As such, a better understanding of predictors, patterns and preventative measures for technique failure is crucial. Moreover, in order to provide insight on trajectories and patterns of technique failure, it would be useful to compare and contrast technique survival between these two home dialysis modalities. With this knowledge, this would allow us to better educate our patients on home dialysis therapies and expand on what to expect with each modality in order to make a more informed decision.

As such, our next Chapter will aim to provide insight on home dialysis technique survival by exploring the differences in patterns and trajectory of technique survival between peritoneal dialysis and home hemodialysis. 


\section{Chapter 2:}

\section{A Comparison of Technique Survival in Canadian Peritoneal Dialysis and Home}

\section{Hemodialysis Patients}

Emilie Trinh $\mathrm{MD}^{1}$, James A. Hanley $\mathrm{PhD}^{2}$, Annie-Claire Nadeau-Fredette $\mathrm{MD}^{3}$, Jeffrey Perl $\mathrm{MD}, \mathrm{SM}^{4}$ and Christopher T Chan $\mathrm{MD}^{5}$.

1. Division of Nephrology, McGill University Health Center, McGill University, Montreal, Quebec, Canada

2. Department of Epidemiology, Biostatistics, and Occupational Health, McGill University, Montreal, Quebec, Canada

3. Division of Nephrology, Hôpital Maisonneuve-Rosemont, Université de Montreal, Montreal, Quebec, Canada

4. Division of Nephrology, St. Michael's Hospital and the Keenan Research Center in the Li Ka Shing Knowledge Institute, St. Michael’s Hospital, Toronto, Ontario, Canada

5. Division of Nephrology, University Health Network, Toronto, Ontario, Canada 
Introduction

Interest in home dialysis has grown in recent years. Indeed, home hemodialysis (HHD) and peritoneal dialysis (PD) offer several clinical benefits for patients with end-stage kidney disease (ESKD) when compared with conventional facility-based thrice-weekly HD. While there has been increasing utilization of home dialysis in many areas of the world ${ }^{1}$, high rates of technique failure remain a challenge. In fact, rates have been reported in up to $25 \%$ of patients within the first year of therapy for both HHD and PD. ${ }^{2-6}$ While previous studies have examined some of the determinants of technique survival for HHD and PD, few studies have compared the trajectory of technique survival between these home modalities.

The primary aim of this study was to better understand home dialysis technique failure by directly comparing time-specific patterns of technique failure between PD and HHD. Our secondary aims were to examine the time dependence of technique survival, the association of patients characteristics with technique failure, causes of technique failure, and changes in technique failure rates over time.

\section{Methods}

This registry-based cohort study included adult patients (aged $\geq 18$ years at time of dialysis initiation) who initiated either PD or HHD in Canada within 1 year of renal replacement therapy (RRT) initiation between January 1, 2000 and December 31, 2012. The end of the observation period was December 31, 2013. For the direct comparison of technique survival between PD and HHD, patients who were treated with both modalities within the first year of dialysis initiation were excluded. Patients were identified from the Canadian Organ Replacement Register (CORR), 
a validated national registry that captures the incidence, prevalence and outcomes of $>99 \%$ chronic dialysis patients and solid-organ transplant recipients in Canada. ${ }^{7}$ Data was collected by completion of a registration form for each patient by the dialysis provider at initiation of dialysis and yearly thereafter. Data from the province of Quebec was excluded due to the need for additional ethics and data permissions. Approval for the study was received from the research ethics board at the University Health Network in Toronto, Canada and from CORR.

\section{Exposure and covariates}

PD was defined as treatment with either continuous ambulatory PD (CAPD) or automated PD (APD), also including home-assisted PD. HHD was defined as any hemodialysis performed at home (conventional, short-daily or nocturnal). Baseline comorbidities were documented by the individual facilities using the CORR registration form at time of dialysis initiation. CORR data has been recently validated. ${ }^{8}$ For patients treated with HHD, vascular access type was ascertained

at time of first HHD treatment. Late referral was defined as never having been seen by a nephrologist before dialysis initiation or first seeing a nephrologist within 3 months before starting dialysis. For each individual center, the average number of new patients per year was calculated. Center size was then categorized as small or large based on a cut-off, defined as the median number of new patients per year for PD and HHD, respectively.

\section{Outcomes}

The primary outcome of interest was technique failure. Technique failure was defined as a transfer to any alternative dialysis modality for a period of $\geq 60$ days. Intervals shorter than 60 days were 
not considered as they were deemed likely to be interruptions due to hospitalization or an acute medical illness.

Secondary outcomes included (1) comparison of technique failure between PD and HHD among different prespecified patient subgroups, (2) association of patient characteristics with technique failure for each home modality, (3) temporal changes in technique failure rates over time, and (4) return rates to initial modality using different technique failure time cut-offs.

\section{Statistical Analyses}

Baseline characteristics of the cohort are presented as medians with interquartile range for continuous variables and proportions for categorical variables. For the direct comparison of technique failure between $\mathrm{HHD}$ and PD, we used a competing risk regression model based on the proportional hazards model for the subdistribution of Fine and Gray. ${ }^{9}$ A Fine and Gray model allowed us to take into account the effect of informative censoring caused by potential differences in rates of mortality and kidney transplantation between PD and HHD, events which were both treated as competing risks. We calculated overall HRs, but, as the association was not proportional over time, year-specific HRs from the time of dialysis initiation were also calculated. To assess the predictors of technique failure for each home dialysis modality independently, a competing risk regression model was also used. Censoring events included loss to follow-up or being alive at the end of the observation period (December 31,2013), whereas mortality and transplantation were treated as competing risks. A comparison of technique survival between HHD and PD was also performed within various pre-specified subgroups (age, year of dialysis initiation, initial HHD vascular access, HHD treatment type) 
Results were validated with a propensity-score (PS) model. The PS was obtained from a logistic regression model using the following covariates at start of follow-up: age, gender, race, BMI, cause of ESKD, era of treatment, diabetes, coronary artery disease, cerebrovascular disease, peripheral vascular disease and smoking status. A 1:1 PS nearest neighbour matching was performed without replacement and technique survival was compared between the matched dialysis modality groups using a Fine and Gray competing risk model. Standardized differences before and after matching were calculated (Figure S1).

\section{Sensitivity Analyses}

To test the robustness of our findings, a sensitivity analysis was performed to assess the primary outcome based on a definition of technique failure of the requirement of at least 90 days on a different dialysis modality (compared to 60 days in the primary analysis).

\section{Results}

\section{Baseline characteristics}

Between January 1, 2000 and December 31, 2012, a total of 15,314 patients were treated with a home dialysis modality within 1 year of RRT initiation in the CORR: 14,461 patients on PD and 853 patients on HHD. Median follow-up was 33.4 months for PD patients and 30.8 months for HHD patients. Table 1 details the baseline characteristics of the entire study cohort, separately for each home dialysis modality. 51 patients were treated with both PD and HHD within the first year and therefore were excluded in the analysis directly comparing technique failure between both modalities. Patients receiving PD were older ( $46 \%$ of patients $\geq 65$ years in PD vs $23 \%$ in HHD) and were also more likely to have diabetic kidney disease while HHD patients were more likely to 
have glomerulonephritis and polycystic kidney disease as a cause of ESKD. Furthermore, HHD patients had fewer comorbidities with a lower prevalence of coronary artery disease, cerebrovascular disease and peripheral vascular disease. The median center size for PD was 30 new patients per year (IQR 19-45) and the median center size for HHD was 5 new patients per year (IQR 3-7). Thus, these values were used as cut-off to categorized small vs. large centers.

\section{Comparison of technique survival between PD and HHD}

There were 5874 technique failure events in PD patients (16.9 per 100 person-years) and 281 events in HHD patients (13.3 per 100 person-years). The median technique survival was 47.9 months for PD and 75.6 months for HHD. Variations in technique failure rates were significantly different between both modalities (Figure 1). Crude rates were the highest during the first year of therapy for both modalities (19.4 per 100 person-years in PD and 22.0 per 100 person-years in HHD). Among HHD patients, rates were significantly lower subsequent to that. In contrast, the decrease in rates was not as pronounced among PD patients

Kaplan-Meier curves comparing unadjusted technique survival in HHD and PD are presented in Figure $2(\log$ rank $\mathrm{p}<0.01) .1$-, 2-, and 5 -year technique survival were $83 \%, 71 \%$ and $43 \%$ in PD vs. $82 \%, 76 \%$, and $59 \%$ in HHD. In a multivariate competing risk model, the overall adjusted risk of technique failure was significantly lower with HHD compared to PD (adjusted HR [adjusted hazard ratio] 0.79; 95\% CI 0.69-0.90, Table 2). However, technique failure comparisons were not proportional over time. For the first year of dialysis, there was no significant difference in technique failure between HHD and PD (AHR 1.13; 95\% CI 0.94-1.36). Subsequent to the first year, the risk of technique failure was significantly lower with HHD (Year 2: AHR 0.46 95\% CI 
0.33-0.65; Year 3: AHR 0.51, 95\% CI 0.35-0.75; Year 4: AHR 0.30, 95\% CI 0.16-0.55; >4 years: AHR $0.65,95 \%$ CI $0.45-0.94$, Table 2). In the propensity-matched cohort, results were similar to the primary analysis.

\section{Subgroup analysis}

The relative risk of technique failure of HHD compared to PD varied among different subgroups (Figure 3, Table S1). Indeed, HHD was associated with lower technique failure in the subgroup of patients aged $<50$ years (AHR 0.60; 95\% CI 0.46-0.78) and 50-65 years (AHR 0.75; 95\% CI 0.610.93) compared to $\mathrm{PD}$, but there was no significant difference among patients $\geq 65$ years old (AHR 1.24; 95\% CI 0.98-1.58). Furthermore, while the adjusted risk of therapy discontinuation was lower among the HHD group for patients initiating dialysis from 2000-2008, this difference was not seen among patients initiating home dialysis in the most recent era of 2009-2012 (AHR 1.01; 95\% CI 0.83-1.23). The relative superior technique survival of HHD compared to PD was also more pronounced in patients who initiated HHD with an arteriovenous access and in those who were treated with slow-nocturnal or short-daily HHD.

\section{Association of patient characteristics with technique failure}

The patient characteristics associated with technique failure are presented in Table 3 . While some factors predictive of technique failure were similar among PD and HHD patients, there were some important differences. Black race, BMI $\geq 30 \mathrm{~kg} / \mathrm{m}^{2}$, smoking, and small facility size were associated with an increased risk of technique failure in both PD and HHD. However, the effect of age on technique survival differed between both modalities. Age $\geq 65$ years was associated with an increased risk in HHD patients whereas there was no significant effect of age in PD patients. There 
was equally a higher technique failure risk in male PD patients while there was no significant gender association among HHD patients. Among PD patients, a primary renal disease of glomerulonephritis and renovascular disease was associated with a lower technique failure risk compared to diabetic kidney disease. Comparatively, only polycystic kidney disease and "other" category as a cause of ESKD were predictive of therapy discontinuation among HHD patients. Lastly, the effect of the era of treatment varied between these two home dialysis modalities. Initiation of therapy in the 2009-2012 era was associated with a lower adjusted risk of technique failure among PD patients, while it was associated with a higher adjusted risk for HHD patients compared to the 2000-2004 cohorts.

\section{Temporal trends in technique failure}

Crude technique failure rates by year of dialysis initiation for PD and HHD are presented in Figure 4. PD technique failure rates appeared to be overall stable over time, while there appears to be an increase in failure rates among HHD since 2002.

\section{Causes of technique failure}

Causes of technique failure were significantly different between PD and HHD (Table 4). While the majority of technique failure occurred for medical reasons in PD (peritonitis, other abdominal complications, inadequate dialysis), the majority of HHD patients experienced technique failure due to social reasons or inadequate resources.

Different technique failure cut-off definitions 
Technique failure events and rates using different definitions ( 30 days, 60 days, 90 days, 180 days and 365 days) are presented in Table 5. The proportion of patients returning to their initial home modality after 30-days of technique failure was $9.4 \%$ for PD and $16 \%$ for HHD within one year. After 60 days, this decreased to $6.5 \%$ for PD and $8.5 \%$ for HHD. After 90 days, only $4.1 \%$ of PD patients and $5.8 \%$ of HHD patients returned to their initial home modality within one year.

\section{Sensitivity Analyses}

Using a technique failure definition of 90 days, the comparisons between PD and HHD yielded very similar adjusted HRs to our primary analysis (Table S2).

\section{Discussion}

In this Canadian study of home dialysis patients, HHD was associated with overall superior technique survival compared to PD. However, patterns of technique survival differed significantly among these modalities. When directly comparing technique survival, the beneficial effect of HHD was only apparent after the first year of dialysis. Moreover, comparisons also varied among subgroups, especially among different age groups and treatment era. Causes of technique failure were equally different between modalities. While the majority of technique failure occurred for medical reasons in $\mathrm{PD}$, the majority of HHD patients experienced technique failure due to social reasons or inadequate resources.

When comparing technique survival between both modalities, the beneficial association with HHD was only apparent after the first year of dialysis. While the highest rates of technique failure were seen during the first year of therapy for both HHD and PD, there was a sharp decrease in failure 
rates subsequent to that for HHD patients while the decrease was not as pronounced among PD patients. These different trajectories may be explained by the different nature of the home dialysis modalities. Indeed, the technical complexity of HHD including machine set-up, self-cannulation and adjustments of hemodialysis parameters may contribute to the initial high rates of technique failure. However, it appears that, once established on the therapy, risk of discontinuation is subsequently much lower. In contrast, while PD may be less technically complex, PD-related clinical complications may occur over time leading patients to discontinue the therapy. Such examples include: the progressive loss of residual kidney function and/or peritoneal membrane dysfunction leading to issues with fluid management and clearance or the occurrence of PDassociated peritonitis.

Determinants of technique failure were also significantly different between both modalities, with the major distinctions seen among older patients and by era of treatment. In fact, we demonstrated that the superior technique survival associated with HHD relative to PD was less pronounced in more recent years and among older patients. The increasing utilization of assisted PD in Canada may contribute to better technique survival with PD in patients $>65$ years old. Moreover, it may also be possible that older patients choose to remain on PD even if they develop a PD-related complication. Our results are consistent with a previous study by Lim et al. examining Australia and New Zealand Dialysis Registry data that showed that elderly patients ( $\geq 65$ years) had a lower risk of technique failure compared with younger patients ( $<50$ years) and with a study by Lobbedez et al. using the French Peritoneal Dialysis Registry that showed superior technique survival with assisted PD compared to self-care PD. ${ }^{10,11}$ 
Technique failure rates have also evolved with time with increasing rates with HHD while more stable rates are seen with PD. These trends over time are consistent with previously published reports and are likely related to evolving patient characteristics, different practice patterns and changing criteria for selection. ${ }^{12,13}$ With significant growth of HHD in Canada in recent years, increasing rates of technique failure may be related to less strict selection criteria with patients with a higher degree of comorbidity being considered for HHD. Indeed, in a previous analysis of CORR, Perl et al. demonstrated significant differences in patient characteristics in more recent cohorts compared to previous cohorts with increasing age, more diabetes and cardiovascular comorbidity. ${ }^{12}$ In contrast, the grossly unchanged rates of technique failure with PD may be attributable to a counterbalance between the selection of older patients with more comorbidities which is associated with a higher risk of failure, and significant reductions PD-related infectious complications over time and the use of assisted PD which are associated with a lower risk. ${ }^{11,14-16}$

Our observed technique failure rates are different compared to previous published reports. For HHD, our 1-year rates of $17 \%$ are lower compared to $25 \%$ in a recent study from the United States. ${ }^{2}$ By comparison, studies from Australia have demonstrated much lower 1-year technique failure rates of $10 \% .{ }^{17}$ In contrast, our rates in PD at 1 year of $18 \%$ are similar to previously published reports. Indeed, rates during the first year have been described at $15-20 \%$ but rates as low as $4.9 \%$ have also been reported. ${ }^{3,5,6,18-20}$ Differences in technique failure rates are likely related to casemix differences between patients in various countries and centers as well as center-specific practices. These include: quality of pre-dialysis education, training approach, training duration, frequency of follow-up care, nurse-to-patient ratios, and availability of psychosocial support in case of patient or caregiver burnout. These factors are crucial to optimize in order to maintain 
patients on home dialysis, but are very difficult to examine using retrospective observational data. Indeed, a very important factor to consider is the differences in training practices. For example, in Australia and New Zealand where technique failure rates are the lowest in HHD, training can be up to $12-16$ weeks. ${ }^{21}$ Comparatively, training is typically shorter in the United States at 3-6 weeks. $^{21}$

Center experience with home dialysis appears to be an important predictor of technique success. We demonstrated that facility size was a significant determinant of technique survival for both HHD and PD with larger centers having lower rates of technique failure, which is consistent with previous reports. ${ }^{12,20,22,23}$ In a recent study of PD patients using data from the Australia and New Zealand Dialysis and Transplant Registry, center-specific factors such as center size, proportion of patients on PD and proportion of patients achieving target phosphate levels were significantly associated with technique failure. ${ }^{22}$ These findings may reflect the degree of experience managing home dialysis patients in addition to the availability of support and resources. Nevertheless, these results highlight that there are potentially modifiable practices that may improve technique survival and further research is needed.

Our findings also add to previous reports examining technique survival among home dialysis patients by evaluating the likelihood of returning to PD or HHD after transfer to another dialysis modality. We found that the proportion of patients returning to their initial home modality within 12 months was overall higher in HHD compared to PD. This difference was largest when using a 30-days definition (9.4\% for PD and 16.0\% for HHD), but became much smaller with definitions of 60 days, 90 days and 180 days. 
This study needs to be interpreted in the context of the observational study design and several limitations should be noted. The use of a large administrative database is subject to limitations arising from data validity and missing data elements. Furthermore, details regarding training, center-specific experience with home dialysis, socioeconomic factors and eligibility for both therapies were not available and likely would have been informative. Information regarding who who was performing dialysis at home (patient, caregiver, home-assisted, etc...) was also not available. Additionally, the exact causes of discontinuation were unknown in a subset of patients and would have helped provide a better clinical picture. Lastly, data from the province of Quebec was excluded due to the need for additional ethics and data permissions. Notwithstanding these limitations, we did study a large multicenter cohort of home dialysis patients with extensive adjustment for comorbid conditions and long follow-up period. To our knowledge, this study is the first to comprehensively compare patterns of technique survival between PD and HHD in a large multicenter cohort.

In this large multi-center Canadian study of home dialysis patients, causes and patterns of technique survival differed significantly between PD and HHD patients. Given the distinct nature of these two modalities in addition to the significant differences in patterns of technique survival, future research should move away from direct technique survival comparisons and instead focus on strategies to improve the retention across all home-based dialysis modalities and allow patients to maintain maximal quality of life on the modality of their choosing. 
Acknowledgments:

The authors acknowledge the staff at the Canadian Organ Replacement Register (CORR) for maintaining the database and the dialysis facilities throughout Canada for submitting information to the CORR. No financial support was received.

Disclosures:

E.T receives speaking honoraria from Baxter Healthcare. J.H has no disclosures to declare. A.C.N.F received a CEC grant and speaking honoraria from Baxter Healthcare, and has a scholarship from Fond de la recherche du Québec en Santé (FRQS). J.P. has received speaking honoraria from Baxter Healthcare and has consulting fees from Baxter Healthcare, Fresenius Medical Care, Otsuka, Janssen Ortho Shire and Takeda, Boehringer-Ingelheim as well as research support from Baxter Healthcare and salary support from Arbor Research Collaborative for Health. C.T.C holds the R. Fraser Elliot Chair in Home Dialysis and consulted for Baxter Inc., NxStage Inc., and Intelomed Inc. 


\section{References}

1. United States Renal Data System. 2016 USRDS annual data report: Epidemiology of kidney disease in the United States. 2016; https://www.usrds.org/2016/view/Default.aspx. Accessed August 10, 2017, 2017.

2. Seshasai RK, Mitra N, Chaknos CM, et al. Factors Associated With Discontinuation of Home Hemodialysis. Am J Kidney Dis. 2016;67(4):629-637.

3. See EJ, Johnson DW, Hawley CM, et al. Risk Predictors and Causes of Technique Failure Within the First Year of Peritoneal Dialysis: An Australia and New Zealand Dialysis and Transplant Registry (ANZDATA) Study. Am J Kidney Dis. 2017.

4. Guo A, Mujais S. Patient and technique survival on peritoneal dialysis in the United States: evaluation in large incident cohorts. Kidney Int Suppl. 2003(88):S3-12.

5. Jaar BG, Plantinga LC, Crews DC, et al. Timing, causes, predictors and prognosis of switching from peritoneal dialysis to hemodialysis: a prospective study. BMC Nephrol. 2009;10:3.

6. Lee S, Kim H, Kim KH, et al. Technique failure in Korean incident peritoneal dialysis patients: a national population-based study. Kidney Res Clin Pract. 2016;35(4):245-251.

7. Canadian Institute for Health Information. Data Quality Documentation for Users: Canadian Organ Replacement Register, 2005 to 2014 Data. Canadian Institute for Health Information. 2009.

8. Moist LM, Richards HA, Miskulin D, et al. A validation study of the Canadian Organ Replacement Register. Clin J Am Soc Nephrol. 2011;6(4):813-818.

9. Fine JP, Gray RJ. A Proportional Hazards Model for the Subdistribution of a Competing Risk. Journal of the American Statistical Association. 1999;94(446):496-509. 
10. Lim WH, Dogra GK, McDonald SP, Brown FG, Johnson DW. Compared with younger peritoneal dialysis patients, elderly patients have similar peritonitis-free survival and lower risk of technique failure, but higher risk of peritonitis-related mortality. Perit Dial Int. 2011;31(6):663671.

11. Lobbedez T, Verger C, Ryckelynck JP, Fabre E, Evans D. Is assisted peritoneal dialysis associated with technique survival when competing events are considered? Clin J Am Soc Nephrol. 2012;7(4):612-618.

12. Perl J, Na Y, Tennankore KK, Chan CT. Temporal Trends and Factors Associated with Home Hemodialysis Technique Survival in Canada. Clin J Am Soc Nephrol. 2017.

13. Perl J, Wald R, Bargman JM, et al. Changes in patient and technique survival over time among incident peritoneal dialysis patients in Canada. Clin J Am Soc Nephrol. 2012;7(7):11451154.

14. Nessim SJ, Bargman JM, Austin PC, Story K, Jassal SV. Impact of age on peritonitis risk in peritoneal dialysis patients: an era effect. Clin J Am Soc Nephrol. 2009;4(1):135-141.

15. Whaley-Connell A, Pavey BS, Satalowich R, et al. Rates of continuous ambulatory peritoneal dialysis-associated peritonitis at the University of Missouri. Adv Perit Dial. 2005;21:7275.

16. Ozisik L, Ozdemir FN, Tanriover MD. The changing trends of peritoneal dialysis related peritonitis and novel risk factors. Ren Fail. 2015;37(6):1027-1032.

17. Jun M, Jardine MJ, Gray N, et al. Outcomes of extended-hours hemodialysis performed predominantly at home. Am J Kidney Dis. 2013;61(2):247-253.

18. Pulliam J, Li NC, Maddux F, Hakim R, Finkelstein FO, Lacson E, Jr. First-year outcomes of incident peritoneal dialysis patients in the United States. Am J Kidney Dis. 2014;64(5):761-769. 
19. Kolesnyk I, Dekker FW, Boeschoten EW, Krediet RT. Time-dependent reasons for peritoneal dialysis technique failure and mortality. Perit Dial Int. 2010;30(2):170-177.

20. Afolalu B, Troidle L, Osayimwen O, Bhargava J, Kitsen J, Finkelstein FO. Technique failure and center size in a large cohort of peritoneal dialysis patients in a defined geographic area. Perit Dial Int. 2009;29(3):292-296.

21. Rioux JP, Marshall MR, Faratro R, Hakim R, Simmonds R, Chan CT. Patient selection and training for home hemodialysis. Hemodial Int. 2015;19 Suppl 1:S71-79.

22. Htay H, Cho Y, Pascoe EM, et al. Multicenter Registry Analysis of Center Characteristics Associated with Technique Failure in Patients on Incident Peritoneal Dialysis. Clin J Am Soc Nephrol. 2017;12(7):1090-1099.

23. Plantinga LC, Fink NE, Finkelstein FO, Powe NR, Jaar BG. Association of peritoneal dialysis clinic size with clinical outcomes. Perit Dial Int. 2009;29(3):285-291. 


\section{Legend to Figures}

Figure 1: Crude rates of technique failure by time from dialysis initiation in home hemodialysis and peritoneal dialysis

Figure 2: Unadjusted technique survival comparison between home hemodialysis and peritoneal dialysis in Canada 2000-2012

Figure 3: Crude rates of technique failure over time in home hemodialysis and peritoneal dialysis

Figure 4: Adjusted hazard ratios of technique failure comparing home hemodialysis with peritoneal dialysis in specific patient subgroups

Reference group: PD 
Table 1: Patient characteristics at home dialysis initiation, 2000 to 2012

\begin{tabular}{|c|c|c|}
\hline & Peritoneal Dialysis & Home Hemodialysis \\
\hline $\mathbf{N}$ & 14461 & 853 \\
\hline \multicolumn{3}{|l|}{ Age, \% } \\
\hline$<50$ years & 23 & 36 \\
\hline 50-65 years & 31 & 41 \\
\hline$\geq 65$ years & 46 & 23 \\
\hline Male gender, $\%$ & 59 & 67 \\
\hline \multicolumn{3}{|l|}{ Race, $\%$} \\
\hline Caucasian & 68 & 72 \\
\hline Asian & 9 & 6 \\
\hline Black & 4 & 7 \\
\hline Other & 20 & 14 \\
\hline \multicolumn{3}{|l|}{ Cause of ESKD, $\%$} \\
\hline Diabetes & 36 & 28 \\
\hline Glomerulonephritis & 19 & 23 \\
\hline Renal Vascular Disease & 18 & 11 \\
\hline Polycystic Kidney Disease & 5 & 13 \\
\hline Other & 19 & 23 \\
\hline Unknown & 3 & 2 \\
\hline \multicolumn{3}{|l|}{ BMI category, \% } \\
\hline$<18.5 \mathrm{~kg} / \mathrm{m}^{2}$ & 3 & 3 \\
\hline $18.5-24.9 \mathrm{~kg} / \mathrm{m}^{2}$ & 35 & 28 \\
\hline $25-29.9 \mathrm{~kg} / \mathrm{m}^{2}$ & 32 & 26 \\
\hline$>30 \mathrm{~kg} / \mathrm{m}^{2}$ & 23 & 34 \\
\hline Unknown & 7 & 9 \\
\hline \multicolumn{3}{|l|}{ Comorbidity Conditions, \% } \\
\hline Diabetes & 8 & 10 \\
\hline Coronary artery disease & 24 & 19 \\
\hline Cerebrovascular disease & 10 & 6 \\
\hline Peripheral artery disease & 13 & 8 \\
\hline Smoker & 12 & 11 \\
\hline Malignancy & 8 & 10 \\
\hline Lung disease & 6 & 1 \\
\hline \multicolumn{3}{|l|}{ Region, \% } \\
\hline Atlantic & 9 & 3 \\
\hline Ontario & 50 & 69 \\
\hline
\end{tabular}




\begin{tabular}{|c|c|c|}
\hline West/Prairie & 41 & 28 \\
\hline \multicolumn{3}{|l|}{ Facility size $* \%$} \\
\hline Small & 48 & 52 \\
\hline Large & 52 & 48 \\
\hline \multicolumn{3}{|l|}{ Referral to nephrology, \% } \\
\hline Late referral $(<90-$ days $)$ & 16 & 19 \\
\hline $\begin{array}{l}\text { Referral to nephrology, days } \\
\text { (median, IQR) }\end{array}$ & $600(159-1518)$ & $851(144-2166)$ \\
\hline \multicolumn{3}{|l|}{ Era \% } \\
\hline $2000-2004$ & 35 & 14 \\
\hline $2005-2008$ & 32 & 31 \\
\hline 2009-2012 & 33 & 55 \\
\hline \multicolumn{3}{|l|}{$\begin{array}{l}\text { Access type at initiation of } \\
\text { dialysis, \% }\end{array}$} \\
\hline Arteriovenous fistula/graft & $\mathrm{n} / \mathrm{a}$ & 39 \\
\hline Central venous catheter & $\mathrm{n} / \mathrm{a}$ & 32 \\
\hline Unknown & $\mathrm{n} / \mathrm{a}$ & 29 \\
\hline \multicolumn{3}{|l|}{ Time of starting therapy, \% } \\
\hline Incident & 72 & 22 \\
\hline$<3$-months & 14 & 28 \\
\hline 3-6 months & 8 & 23 \\
\hline 6-12 months & 6 & 27 \\
\hline Prior IHD & 27 & 74 \\
\hline \multicolumn{3}{|l|}{ PD type, \% } \\
\hline CAPD & 71 & $\mathrm{n} / \mathrm{a}$ \\
\hline APD & 29 & $\mathrm{n} / \mathrm{a}$ \\
\hline \multicolumn{3}{|l|}{ HHD type, \% } \\
\hline Conventional & $\mathrm{n} / \mathrm{a}$ & 52 \\
\hline Short daily & $\mathrm{n} / \mathrm{a}$ & 14 \\
\hline Slow nocturnal & $\mathrm{n} / \mathrm{a}$ & 34 \\
\hline
\end{tabular}

BMI, body mass index; IHD, in-center hemodialysis; PD, peritoneal dialysis; CAPD, continuous ambulatory peritoneal dialysis; APD, automated peritoneal dialysis; HHD, home hemodialysis

* Facility size definition:

PD: small ( $<30$ new patients per year) and large ( $\geq 30$ new patients per year)

HHD: small $(<5$ new patients per year) and large $(\geq 5$ new patients per year) 
Table 2: Adjusted hazard ratios for technique failure comparing home hemodialysis with peritoneal dialysis

\begin{tabular}{|c|c|}
\hline & $\begin{array}{c}\text { HR (95\% CI) } \\
\text { HHD:PD }\end{array}$ \\
(Reference group: PD)
\end{tabular}

$\mathrm{HR}$, hazard ratio; HHD, home hemodialysis; PD, peritoneal dialysis

* Adjusted for age, gender, race, BMI, cause of ESKD, comorbidities, smoking status, facility size and era. 
Table 3: Association of patient characteristics with technique failure

\begin{tabular}{|c|c|c|c|c|}
\hline & \multicolumn{2}{|c|}{ Peritoneal Dialysis } & \multicolumn{2}{|c|}{ Home Hemodialysis } \\
\hline & AHR (95\% CI) & P value & AHR (95\% CI) & $P$ value \\
\hline \multicolumn{5}{|l|}{ Age } \\
\hline$<50$ years & 1 (Reference) & & 1 (Reference) & \\
\hline $50-65$ years & $1.04(0.96-1.12)$ & 0.39 & $1.04(0.78-1.40)$ & 0.77 \\
\hline$\geq 65$ years & $0.99(0.91-1.08)$ & 0.83 & $1.91(1.37-2.65)$ & $<0.001$ \\
\hline Male gender & $1.08(1.02-1.15)$ & 0.01 & $1.14(0.88-1.47)$ & 0.31 \\
\hline \multicolumn{5}{|l|}{ Race, $\%$} \\
\hline Caucasian & 1 (Reference) & & 1 (Reference) & \\
\hline Asian & $0.90(0.80-1.01)$ & 0.07 & $0.84(0.50-1.39)$ & 0.50 \\
\hline Black & $1.32(1.15-1.52)$ & $<0.001$ & $1.76(1.12-2.74)$ & 0.01 \\
\hline Other & $1.06(0.98-1.14)$ & 0.15 & $1.48(1.09-2.02)$ & 0.01 \\
\hline \multicolumn{5}{|l|}{ Cause of ESKD } \\
\hline Diabetes & 1 (Reference) & & 1 (Reference) & \\
\hline Glomerulonephritis & $0.92(0.84-1.00)$ & 0.05 & $0.79(0.57-1.10)$ & 0.16 \\
\hline $\begin{array}{l}\text { Renal Vascular } \\
\text { Disease }\end{array}$ & $0.91(0.83-0.99)$ & 0.03 & $1.18(0.82-1.70)$ & 0.38 \\
\hline $\begin{array}{l}\text { Polycystic Kidney } \\
\text { Disease }\end{array}$ & $0.98(0.87-1.12)$ & 0.82 & $0.61(0.38-0.97)$ & 0.04 \\
\hline Other & $0.88(0.80-0.96)$ & 0.005 & $0.67(0.47-0.97)$ & 0.03 \\
\hline \multicolumn{5}{|l|}{ BMI category } \\
\hline$<18.5 \mathrm{~kg} / \mathrm{m}^{2}$ & $1.06(0.87-1.29)$ & 0.58 & $1.13(0.49-2.60)$ & 0.78 \\
\hline $18.5-24.9 \mathrm{~kg} / \mathrm{m}^{2}$ & 1 (Reference) & & 1 (Reference) & \\
\hline $25-29.9 \mathrm{~kg} / \mathrm{m}^{2}$ & $1.17(1.09-1.26)$ & $<0.001$ & $1.30(0.93-1.81)$ & 0.12 \\
\hline$>30 \mathrm{~kg} / \mathrm{m}^{2}$ & $1.42(1.31-1.53)$ & $<0.001$ & $1.65(1.23-2.23)$ & 0.001 \\
\hline \multicolumn{5}{|l|}{ Comorbidity Conditions } \\
\hline Diabetes & $1.08(0.96-1.21)$ & 0.20 & $1.24(0.81-1.90)$ & 0.32 \\
\hline $\begin{array}{l}\text { Coronary artery } \\
\text { disease }\end{array}$ & $0.95(0.88-1.02)$ & 0.16 & $0.77(0.55-1.08)$ & 0.13 \\
\hline $\begin{array}{l}\text { Cerebrovascular } \\
\text { disease }\end{array}$ & $0.95(0.85-1.05)$ & 0.30 & $1.10(0.69-1.75)$ & 0.68 \\
\hline $\begin{array}{l}\text { Peripheral artery } \\
\text { disease }\end{array}$ & $0.96(0.87-1.06)$ & 0.44 & $1.21(0.82-1.80)$ & 0.33 \\
\hline Smoker & $1.14(1.05-1.24)$ & 0.002 & $1.47(1.01-2.14)$ & 0.04 \\
\hline Facility size* & & & & \\
\hline
\end{tabular}




\begin{tabular}{|l|c|c|c|c|}
\hline Small & 1 (Reference) & & 1 (Reference) & \\
\hline Large & $0.89(0.84-0.95)$ & $<0.001$ & $0.74(0.58-0.93)$ & 0.01 \\
\hline Referral to nephrology & & & & \\
\hline $\begin{array}{c}\text { Late referral (<90- } \\
\text { days) }\end{array}$ & $0.98(0.90-1.06)$ & 0.57 & $1.14(0.94-1.55)$ & 0.40 \\
\hline Era & & & & \\
\hline $\mathbf{2 0 0 0 - 2 0 0 4}$ & 1 (Reference) & & 1 (Reference) & \\
\hline $\mathbf{2 0 0 5 - 2 0 0 8}$ & $0.99(0.93-1.06)$ & 0.76 & $1.22(0.80-1.86)$ & 0.35 \\
\hline $\mathbf{2 0 0 9 - 2 0 1 2}$ & $0.88(0.82-0.95)$ & 0.001 & $1.56(1.05-2.32)$ & 0.02 \\
\hline PD type & & & & \\
\hline CAPD & $1($ Reference) & & $\mathrm{n} / \mathrm{a}$ & \\
\hline APD & $1.01(0.95-1.08)$ & 0.77 & $\mathrm{n} / \mathrm{a}$ & \\
\hline HHD type & & & & \\
\hline Conventional & $\mathrm{n} / \mathrm{a}$ & & $1($ Reference) & \\
\hline Nocturnal & $\mathrm{n} / \mathrm{a}$ & & $0.83(0.58-1.17)$ & 0.28 \\
\hline Short-daily & $\mathrm{n} / \mathrm{a}$ & & $0.87(0.67-1.13)$ & 0.30 \\
\hline
\end{tabular}

ESKD, end-stage kidney disease; BMI, body mass index; PD, peritoneal dialysis; CAPD, continuous ambulatory peritoneal dialysis; APD, automated peritoneal dialysis; HHD, home hemodialysis

* Facility size definition:

PD: small ( $<30$ new patients per year) and large ( $\geq 30$ new patients per year)

HHD: small $(<5$ new patients per year) and large $(\geq 5$ new patients per year) 
Table 4: Causes of technique failure in peritoneal dialysis and home hemodialysis patients

\begin{tabular}{|l|c|c|}
\hline \multicolumn{1}{|c|}{ Cause } & Peritoneal Dialysis (\%) & Home Hemodialysis (\%) \\
\hline Peritonitis & 13 & n/a \\
\hline Other abdominal complications & 7 & n/a \\
\hline Inadequate dialysis & 18 & 6 \\
\hline Social & 23 & 33 \\
\hline Insufficient resources & 2 & 17 \\
\hline Other & 28 & 21 \\
\hline Unknown & 9 & 23 \\
\hline
\end{tabular}


Table 5: Technique failure event rates by different cut-off definitions

\begin{tabular}{|l|c|c|c|c|c|c|}
\hline & \multicolumn{3}{|c|}{ Peritoneal Dialysis } & \multicolumn{3}{c|}{ Home Hemodialysis } \\
\hline Events & $\begin{array}{c}\text { Events / } \\
100 \text { person- } \\
\text { year }\end{array}$ & $\begin{array}{c}\text { Proportion } \\
\text { returning to PD } \\
\text { within 1 year } \\
(\%)\end{array}$ & Events & $\begin{array}{c}\text { Events / 100 } \\
\text { person-year }\end{array}$ & $\begin{array}{c}\text { Proportion } \\
\text { returning to } \\
\text { HHD within 1 } \\
\text { year } \\
(\%)\end{array}$ \\
\hline 30-days & 6066 & 18.3 & $9.4 \%$ & 306 & 14.9 & $16.0 \%$ \\
\hline 60-days & 5874 & 17.4 & $6.5 \%$ & 281 & 13.3 & $8.5 \%$ \\
\hline 90-days & 5729 & 16.7 & $4.1 \%$ & 273 & 12.8 & $5.8 \%$ \\
\hline 180-days & 5569 & 16.0 & $1.3 \%$ & 265 & 12.3 & $3.0 \%$ \\
\hline 365-days & 5494 & 15.6 & $\mathrm{n} / \mathrm{a}$ & 257 & 11.7 & $\mathrm{n} / \mathrm{a}$ \\
\hline
\end{tabular}

PD, peritoneal dialysis; HHD, home hemodialysis 
Figure 1: Crude rates of technique failure by time from dialysis initiation in home hemodialysis and peritoneal dialysis

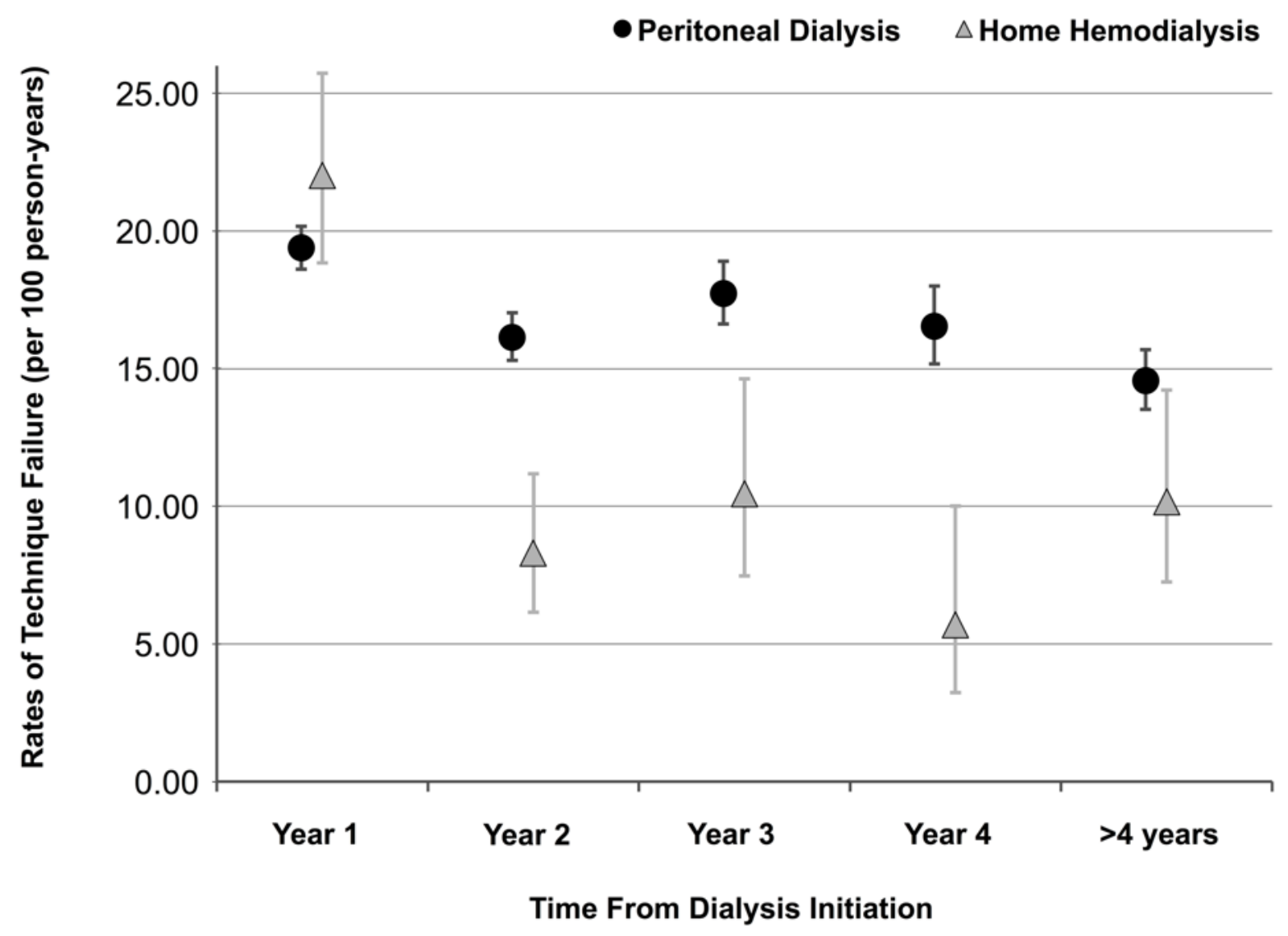


Figure 2: Unadjusted technique survival comparison between home hemodialysis and peritoneal dialysis in Canada 2000-2012

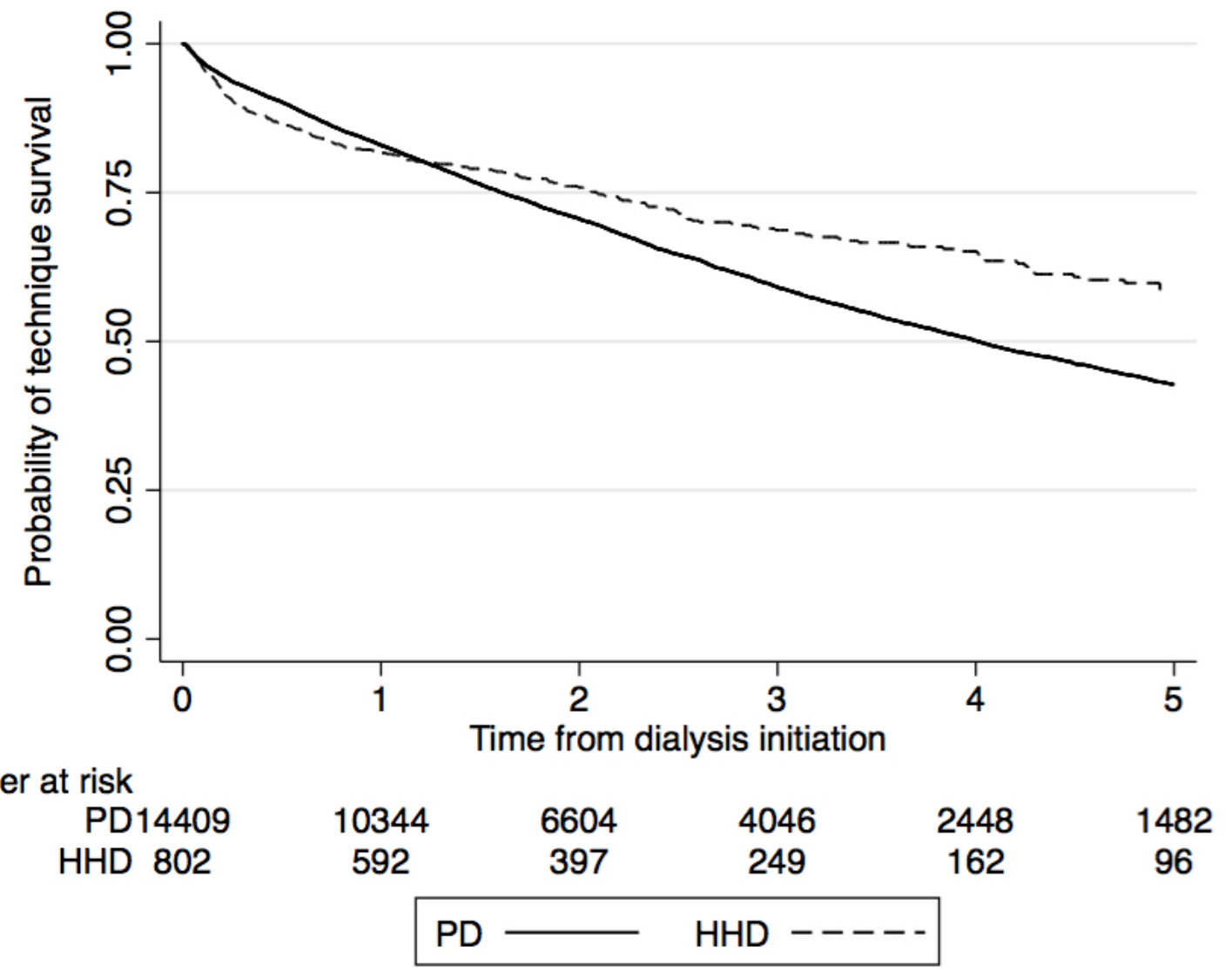


Figure 3: Adjusted hazard ratios of technique failure comparing home hemodialysis with peritoneal dialysis in specific patient subgroups

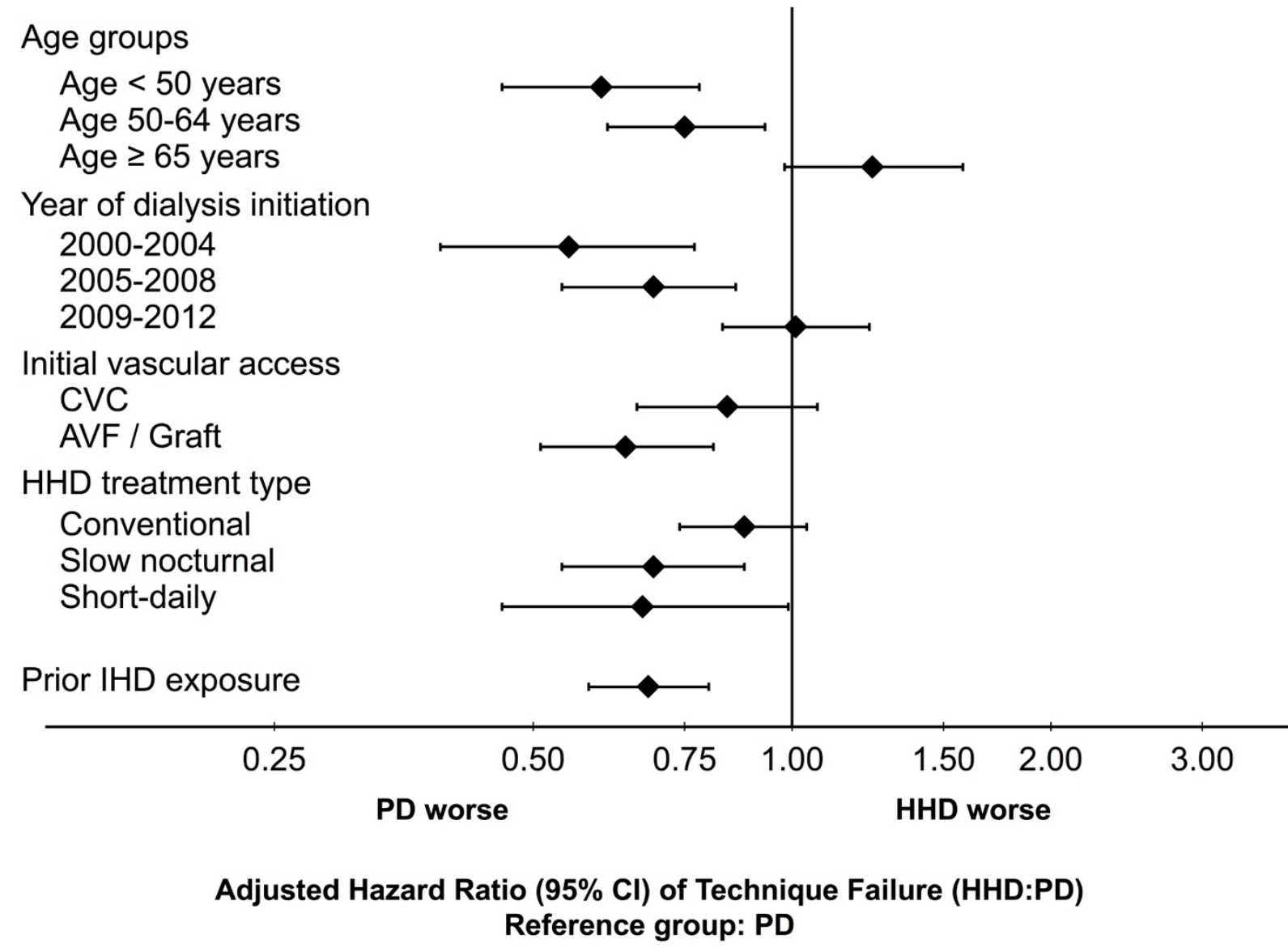


Figure 4: Crude rates of technique failure over time in home hemodialysis and peritoneal dialysis

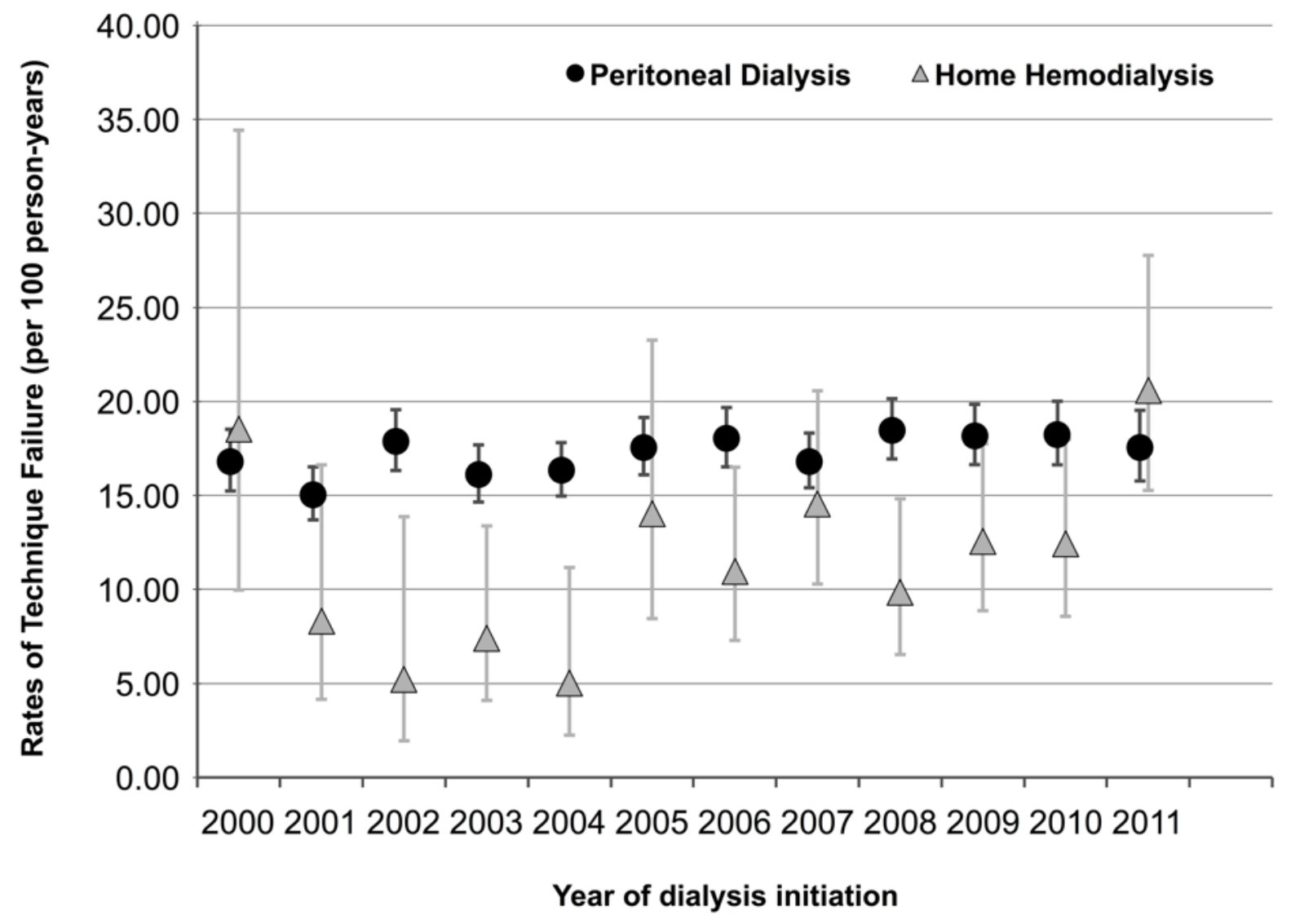


Supplemental Material

Table S1: Adjusted hazard ratios for technique failure comparing home hemodialysis with peritoneal dialysis in specific patient subgroups

\begin{tabular}{|c|c|}
\hline & $\begin{array}{c}\text { AHR (95\% CI) } \\
\text { HHD:PD } \\
\text { (reference group: PD)* }\end{array}$ \\
\hline \multicolumn{2}{|l|}{ Age subgroups } \\
\hline Age $<50$ years & $0.60(0.46-0.78)$ \\
\hline Age $50-65$ years & $0.75(0.61-0.93)$ \\
\hline Age $\geq 65$ years & $1.24(0.98-1.58)$ \\
\hline \multicolumn{2}{|l|}{ Year of dialysis initiation } \\
\hline $2000-2004$ & $0.55(0.39-0.77)$ \\
\hline $2005-2008$ & $0.69(0.54-0.86)$ \\
\hline $2009-2012$ & $1.01(0.83-1.23)$ \\
\hline \multicolumn{2}{|l|}{ Initial vascular access } \\
\hline Central venous catheter & $0.84(0.66-1.07)$ \\
\hline Arteriovenous fistula/graft & $0.64(0.51-0.81)$ \\
\hline \multicolumn{2}{|l|}{ HHD treatment type } \\
\hline Conventional & $0.88(0.74-1.04)$ \\
\hline Slow nocturnal & $0.69(0.54-0.88)$ \\
\hline Short-daily & $0.67(0.46-0.99)$ \\
\hline Prior IHD exposure & $0.68(0.58-0.80)$ \\
\hline
\end{tabular}

AHR, adjusted hazard ratio; HHD, home hemodialysis; PD, peritoneal dialysis; IHD, in-center hemodialysis

* Adjusted for age, gender, race, BMI, cause of ESKD, comorbidities, smoking status, facility size and era. 
Table S2: Adjusted hazard ratios for technique failure comparing home hemodialysis with peritoneal dialysis (90-day technique failure definition)

\begin{tabular}{|c|c|c|}
\hline & $\begin{array}{c}\text { HR (95\% CI) } \\
\text { HHD:PD } \\
\text { (reference group: PD) }\end{array}$ & P value \\
\hline $\begin{array}{l}\text { Multivariate adjusted } \\
\text { competing risk model* }\end{array}$ & & \\
\hline Overall & $0.79(0.69-0.91)$ & 0.001 \\
\hline Year 1 & $1.14(0.94-1.38)$ & 0.18 \\
\hline Year 2 & $0.49(0.35-0.69)$ & $<0.001$ \\
\hline Year 3 & $0.49(0.33-0.73)$ & $<0.001$ \\
\hline Year 4 & $0.28(0.15-0.53)$ & $<0.001$ \\
\hline >4 years & $0.67(0.47-0.97)$ & 0.03 \\
\hline & & \\
\hline Propensity-matched model & & 0.002 \\
\hline Overall & $0.76(0.64-0.90)$ & 0.95 \\
\hline Year 1 & $1.01(0.79-1.29)$ & $<0.001$ \\
\hline Year 2 & $0.48(0.32-0.72)$ & 0.001 \\
\hline Year 3 & $0.44(0.28-0.70)$ & 0.001 \\
\hline Year 4 & $0.29(0.14-0.60)$ & 0.51 \\
\hline >4 years & $0.84(0.49-1.43)$ & \\
\hline
\end{tabular}

* Adjusted for age, gender, race, BMI, cause of ESRD, comorbidities, smoking status, facility size and era. 
Figure S1: Standardized differences before and after propensity-matching

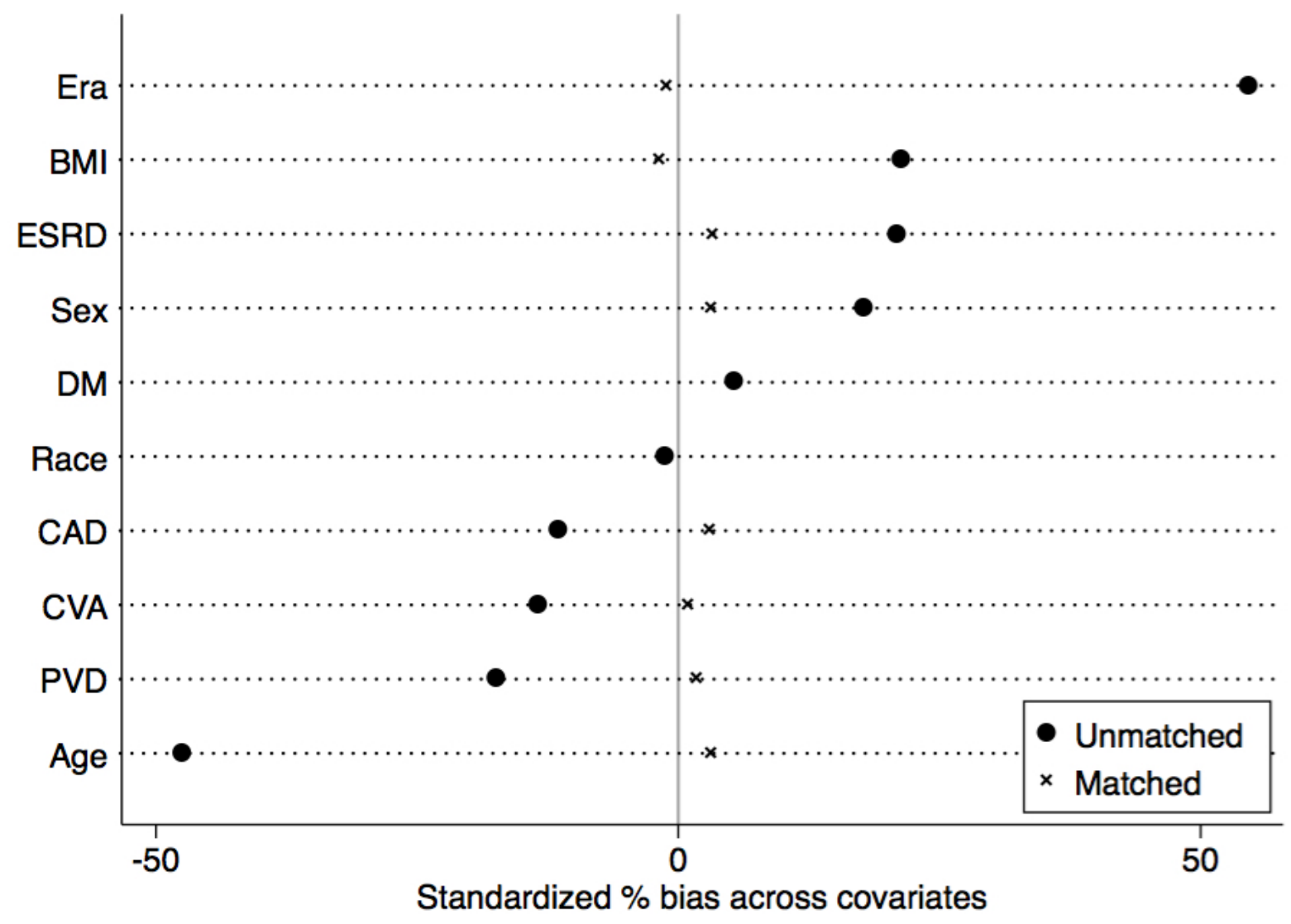

BMI, body mass index; ESRD, end-stage renal disease; DM, diabetes; CAD, coronary artery disease; CVA, cerebrovascular accident; PVD, peripheral vascular disease 


\section{Chapter 3: Conclusions}

High rates of technique failure remain a challenge and finding strategies to improve technique survival in order to maintain patients on home therapies is of the utmost importance. To increase the prevalent use of home dialysis, not only is it important to increase incident utilization, but it is equally important to maximize home dialysis longevity.

In the first chapter entitled "Technique Survival Home Dialysis: A Review", a literature review identified what is currently known about technique survival in peritoneal dialysis and home hemodialysis, exploring challenges in accurate definitions, and elaborating on complications, reported rates, predictors and causes of technique failure.

The second chapter entitled "A Comparison of Technique Survival in Canadian Peritoneal Dialysis and Home Hemodialysis Patients" is a manuscript that explores differences in patterns and trajectory of technique survival between peritoneal dialysis and home hemodialysis in a retrospective study of a large multicenter Canadian cohort. While home hemodialysis was associated with overall lower technique failure (AHR 0.79, 95\% CI 0.69-0.90), comparisons were not proportional over time. In fact, trajectories of technique failure were significantly different between both modalities, which may be explained by the vastly different nature of these modalities. While the highest rates of technique failure were seen during the first year of therapy

for both HHD and PD, there was a sharp decrease in failure rates subsequent to that for HHD patients while the decrease was not as pronounced among PD patients. Comparisons also varied among subgroups, especially among different age groups and treatment era. Predictors and causes of technique failure were equally significantly different between these modalities. We also found 
that technique failure rates have evolved with time with increasing rates with HHD while more stable rates are seen with PD.

This present thesis has contributed to a more thorough understanding of home dialysis technique survival and is the first study, to our knowledge, to comprehensively compare patterns of technique survival between PD and HHD in a large multicenter cohort. Moving forward, it is imperative to better examine home dialysis technique survival. Given the distinct nature of these two therapies and the significant differences in technique survival patterns, future research should move away from direct comparisons and instead focus on strategies to improve retention across all home-based modalities. This may help allow patients to maintain maximal quality of life on the modality of their choosing.

Future studies should focus on modifiable practices that can help improve technique survival including: 1) optimizing patient selection and recruitment 2) improving patient training practices 3) better understanding of modifiable center-specific practices associated with technique success and associations with clinical outcomes 4) providing adequate resources to support patients at home 5) evaluating optimal frequency of follow-up 6) managing problematic or non-compliant patients and 7) helping to optimize transition to another renal replacement therapy if technique failure unavoidable. 